\title{
BJMHR
}

British Journal of Medical and Health Research

Journal home page: www.bjmhr.com

\section{The Relationship Of Glycaemic Exposure (HbA1C) As Risk Factor For Development Of Diabetic Retinopathy}

\author{
Kishor P. Kadu ${ }^{1}$, Smita K. Kadu ${ }^{2 *}$, Vishakha T. Vatkar ${ }^{3}$, Sharayu A. Bhore ${ }^{4}$ \\ 1.Consultant, Epione hospital, Amravati \\ 2.Professor and Head, Dr. PDMMC Hospital, Amravati \\ 3.Junior Resident, Dr. PDMMC Hospital, Amravati \\ 4.Junior Resident, Dr. PDMMC Hospital, Amravati
}

\begin{abstract}
Diabetic Retinopathy (DR) is emerging fastly as one of the commonest causes of blindness. Globally in developed countries over 2.5 million people are blind due to diabetes. The risk of developing diabetic retinopathy or other micro-vascular complications of diabetes depends on both the duration and severity of hyperglycaemia. Present study is done to determine the prevalence of diabetic retinopathy (DR) in association with raise in $\mathrm{HbA1c}$ and also to correlate the severity of Diabetic retinopathy with the levels of HbA1c. A cross sectional study was conducted among 200 patients with diabetes mellitus attending the institute. All patients were subjected to relevant investigations, detailed slit lamp and dilated retinal examination. Diabetic Retinopathy was graded as per ETDRS categories. Among 200 patients, male: female ratio was 1.17. Majority of the patients were in the age group of 41 to 60 years. Present study shows that 52 had mild NPDR, 15 had moderate to severe NPDR and 13 had PDR. Present study showed as the $\mathrm{HbA1c}$ level increases severity of the diabetic retinopathy also increases and that Hba1c is an important and an independent factor responsible for development of diabetic retinopathy in patients with diabetes mellitus.
\end{abstract}

Keywords: HbA1c, Diabetic retinopathy.

Please cite this article as: Kadu SK et al., The Relationship Of Glycaemic Exposure (HbA1C) As Risk Factor For Development Of Diabetic Retinopathy . British Journal of Medical and Health Research 2021. 
*Corresponding Author Email: drsmitakadu33@ gmail.com

Received 04 February 2021, Accepted 2 March 2021

\section{INTRODUCTION}

Diabetes mellitus (DM), commonly known as diabetes, is a group of metabolic disorders characterized by a high blood sugar level over a prolonged period of time. In contrast to western countries where the largest increase in the numbers of diabetic patients are elderly population aged >64 years, the majority part of the increase in Asia will occur among the population aged 45-64 years. India is set to emerge as the diabetic capital of the world. According to the WHO, 31.7 million people were affected by diabetes mellitus (DM) in India in the year 2000. This figure is estimated to rise to 79.4 million by 2030 , the largest number in any nation in the world. Almost two-third of all Type 2 and almost all Type 1 diabetics are expected to develop diabetic retinopathy (DR) over a period of time. Globally in developed countries over 2.5 million are blind due to diabetes .Diabetic retinopathy is the most common cause of preventable blindness in working aged adults.

Diabetic retinopathy (DR) is a major complication of diabetes mellitus (DM), which remains a leading cause of visual loss in working-age populations. DIABETIC RETINOPATHY (DR) is divided into two stages: non-proliferative diabetic retinopathy (NPDR) and proliferative diabetic retinopathy (PDR). NPDR represents the early stage of DR, wherein increased vascular permeability and capillary occlusion are two main observations in the retinal vasculature. During this stage, retinal pathologies including micro-aneurysms, haemorrhages and hard exudates can be detected by fundus photography although the patients may be asymptomatic. PDR, a more advanced stage of DR, is characterized by neovascularization. During this stage, the patients may experience severe vision impairment when the new abnormal vessels bleed into the vitreous (vitreous haemorrhage) or when tractional retinal detachment is present. The most common cause of vision loss in patients with DIABETIC RETINOPATHY is diabetic macular oedema (DME). DME is characterized by swelling or thickening of the macula due to sub- and intra-retinal accumulation of fluid in the macula triggered by the breakdown of the blood-retinal barrier (BRB). Earliest responses of the retinal blood vessels to hyperglycaemia are dilatation of blood vessels and blood flow changes. These changes are considered to be a metabolic auto-regulation to increase retinal metabolism in diabetic subjects ${ }^{4}$. Pericyte loss is another hallmark of the early events of DIABETIC RETINOPATHY. Evidence of apoptosis of pericytes triggered by high glucose has been shown in both in vitro and in vivo studies ${ }^{5,6}$. Since pericytes are responsible for providing structural support for capillaries, loss of them leads to localized out-pouching of capillary walls. This process is associated with micro-aneurysm formation, which is the earliest clinical sign of 
DIABETIC RETINOPATHY ${ }^{7}$. In addition to pericyte loss, apoptosis of endothelial cells and thickening of the basement membrane are also detected during the pathogenesis of DIABETIC RETINOPATHY, which collectively contribute to the impairment of the BRB

The haemoglobin A1c test tells you your average level of blood sugar over the past 2 to 3 months. It's also called HbA1c, glycated haemoglobin test, and glycol-haemoglobin. When glucose builds up in your blood, it binds to the haemoglobin in your red blood cells. The A1c test measures how much glucose is bound. Red blood cells live for about 3 months, so the test shows the average level of glucose in your blood for the past 3 months. If your glucose levels have been high over recent weeks, your haemoglobin A1c test will be higher.

\begin{tabular}{|c|c|c|}
\hline \multicolumn{2}{|c|}{ Alc and Blood Sugar } & \multirow{2}{*}{$\begin{array}{l}\text { A1c Test } \\
\text { Results }\end{array}$} \\
\hline A1c (\%) & Average Blood Sugar (mg/dL) & \\
\hline 4 & 68 & \\
\hline 5 & 97 & $\begin{array}{l}\text { Diabetes } \\
65.5 \% \text { r. }\end{array}$ \\
\hline 6 & 126 & \\
\hline 7 & 152 & \\
\hline 8 & 183 & $\begin{array}{l}\begin{array}{l}\text { Prediat } \\
5.7 \text { to } 6\end{array} \\
\text { S }\end{array}$ \\
\hline 9 & 212 & \\
\hline 10 & 240 & \\
\hline 11 & 269 & $\begin{array}{l}\text { Normal } \\
\text { Below } 5.7 \%\end{array}$ \\
\hline 12 & 298 & \\
\hline 13 & 326 & \\
\hline 14 & 355 & \\
\hline
\end{tabular}

\section{Aim of Study}

To study the relationship of glycaemic exposure (HbA1c) to the risk factor of development of diabetic retinopathy.

\section{MATERIALS AND METHOD}

A cross sectional study was conducted in Department of Ophthalmology in patients with diabetes mellitus of more than 5 years of duration, for a period of 6 months. Patients with microalbuminuria, congestive cardiac failure, haematuria, marked hypertension, urinary tract infection, all acute and chronic kidney diseases were excluded from the study. The study was approved from the local Institutional Review Board/ Ethical Committee and follows declaration of Helsinki. A minimum sample size of 200 was calculated by using EPI Software version 2.6 considering confidence limit of $95 \%$. The data was entered and analyzed using IBM SPSS statistics.

A written informed consent from the patients was taken before conducting the interview and examination. The data was collected by getting blood sample for the levels of HbA1c and followed by detailed ophthalmic examination. Thorough ocular evaluation was done on all selected patients both clinically as well as with the help of diagnostic instruments. Visual Acuity was measured using Snellen's charts. Both uncorrected and best corrected visual acuities were noted. Anterior segment evaluation by diffuse torch light and slit lamp examination was done to look for any other associated pathology and other manifestations of 
diabetes like neovascularization of iris, diabetic cataract. Fundus examination-included, Direct ophthalmoscopy done by Heinz ophthalmoscope to visualize central fundus mainly the posterior pole (including the optic disc and macula) where the earliest diabetic changes occur. Indirect ophthalmoscopy was done to visualize the fundus upto periphery. The more peripheral parts of the fundus were visualised to rule out any other pathology and retinal detachments. Gonioscopy was also done to rule out neovascularisation at angle. The grading of Diabetic retinopathy adhered to the ETDRS DIABETIC RETINOPATHY levels. .All the patient were advised to undergo biochemical investigations which were Blood sugar (fasting/PP), HBA1c. Out of 200 subjects included in study, 92 (46\%) were females and 108(54\%) were males. Male: female ratio was 1.17. Majority of patients (55\%) were aged 41-60 years, followed by 61-80 $(28 \%)$ and $20-40$ years $(16 \%)$. Only $2(1 \%)$ patients were aged $>80$ years.

\begin{tabular}{lll}
\hline & No. Of patients & Percentage \\
\hline 20-40 years & 32 & $16 \%$ \\
$41-60$ years & 110 & $55 \%$ \\
61-80 years & 56 & $28 \%$ \\
$>80$ years & 2 & $1 \%$ \\
\hline
\end{tabular}

\begin{tabular}{|c|c|c|c|c|c|c|c|c|c|c|}
\hline \multirow{2}{*}{$\begin{array}{l}\text { Hba1c } \\
\\
\begin{array}{l}\text { Good control } \\
<7 \%(110)\end{array}\end{array}$} & \multicolumn{2}{|c|}{$\begin{array}{l}\text { No } \\
\text { retinopathy } \\
(110)\end{array}$} & \multicolumn{3}{|c|}{$\begin{array}{l}\text { Very mild to } \\
\text { moderate diabetic } \\
\text { retinopathy }(52)\end{array}$} & \multicolumn{3}{|c|}{$\begin{array}{l}\text { Severe to very severe } \\
\text { diabetic retinopathy } \\
(22)\end{array}$} & \multicolumn{2}{|c|}{$\begin{array}{l}\text { Proliferative } \\
\text { diabetic } \\
\text { retinopathy } \\
(16)\end{array}$} \\
\hline & 90 & $\begin{array}{l}81.81 \\
\%\end{array}$ & 17 & 15.4 & $45 \%$ & 3 & $2.72 \%$ & & 0 & $0 \%$ \\
\hline $\begin{array}{l}\text { Fair control } \\
7.1-8.5 \% \\
(69)\end{array}$ & 30 & $\begin{array}{l}43.47 \\
\%\end{array}$ & 30 & 43.47 & $47 \%$ & 7 & $10.14 \%$ & & 4 & $8.69 \%$ \\
\hline $\begin{array}{l}\text { Poor control } \\
>8.5 \% \\
21\end{array}$ & 2 & $9.52 \%$ & 5 & 23.80 & $80 \%$ & 5 & 23.8 & & 9 & $42.87 \%$ \\
\hline $\begin{array}{l}\text { Duration } \\
\text { diabetes }\end{array}$ & of & To DR & & $\begin{array}{l}\text { Mild to } \\
\text { NPDR }\end{array}$ & $\begin{array}{l}\text { to moderate } \\
\text { R }(\%)\end{array}$ & & $\begin{array}{ll}\text { ate } & \text { to } \\
\text { NPDR } & \\
\end{array}$ & & & \\
\hline$<10$ years & & $(45.0$ & & 7 & $(13.46 \%)$ & 4 & $(6.66 \%)$ & & & $7.69 \%)$ \\
\hline $10-20$ years & & $(50.8$ & & 10 & $(19.23 \%)$ & 3 & $(20 \%)$ & 1 & & $7.69 \%)$ \\
\hline $21-40$ years & & $(4.0$ & & 15 & $(28.84 \%)$ & 3 & $(20 \%)$ & 3 & & $3.07 \%)$ \\
\hline$>40$ years & & $(0 \%$ & & 20 & $(38.46 \%)$ & 8 & $(53.33 \%)$ & 8 & & $1.53 \%)$ \\
\hline
\end{tabular}

Patients with $\mathrm{HbA} 1 \mathrm{c}<7 \%$ (good control) has low prevalence of retinopathy (18.18\%), compared to patients having $7.1 \%-8.5 \%$ (fair control) $(57.74 \%$ ) and $>8.5 \%$ (poor control ) $(90.47 \%$ )of HbA1c values. Proliferative diabetic retinopathy was higher in patients with poor control of $\mathrm{HbA1c}(42.87 \%)$ as compared to fair (8.69) and good (0\%) control of HbA1c values. A significant statistical association was found between diabetic retinopathy and $\mathrm{HbAlc}$ values.

\section{DISCUSSION}

In this study, majority of patients had mild to moderate non proliferative diabetic retinopathy compared to very severe non proliferative diabetic retinopathy and proliferative diabetic 
retinopathy. It is important to evaluate the role of glycaemic control for the prevalence of diabetic retinopathy. In different cross-sectional studies, prevalence of different grades of retinopathy have been shown to be of similar order with prevalence of lower grades of retinopathy being higher compared to higher grades or proliferative retinopathy ${ }^{8-12}$.

In this study we have found that the patients having good control of Hbalc values $(<7 \%)$ has low prevalence of developing diabetic retinopathy as compared to patients with Hbalc vales $>7 \%$. There is increase in prevalence as well as severity of diabetic retinopathy with increasing glycaemic control. A similar observation was also made by Mohan et al (2011) ${ }^{13}$ who observed that both glycaemic control as well as albumin level have independent association with occurrence as well as severity of diabetic retinopathy.

\section{CONCLUSION}

From the present study, we can conclude that Hbalc is an important and an independent factor responsible for development of diabetic retinopathy in patients with diabetes mellitus. Glycaemic control and life style modification along with routine $\mathrm{HbA1c}$ in all DM patients for risk determination for DR will help to reduce the prevalence of DR in patients of DM.

\section{REFERENCES}

1. Norman A, Henry H (2015). Hormones. Elsevier. pp. 136-137. ISBN 9780123694447.

2. WHO. October 2013. Archived from the original on 26 August 2013. Retrieved 25 March 2014.

3. Jaypee Brothers Medical Publishers. 2012. p. 235. ISBN 978-93-5025-4899. Archived from the original on 14 October 2015.

4. Krishnasamy S, Abell TL (July 2018). "Diabetic Gastroparesis: Principles and Current Trends in Management". Diabetes Therapy. 9 (Suppl 1): 1-42. doi:10.1007/s13300018-0454-9. PMC 6028327. PMID 29934758.

5. Saedi, E; Gheini, MR; Faiz, F; Arami, MA (15 September 2016). "Diabetes mellitus and cognitive impairments". World Journal of Diabetes. 7 (17): 41222. doi:10.4239/wjd.v7.i17.412. PMC 5027005. PMID 27660698.

6. Jump up to: ${ }^{\mathbf{b}}$ Chiang JL, Kirkman MS, Laffel LM, Peters AL (July 2014). "Type 1 diabetes through the life span: a position statement of the American Diabetes Association". Diabetes Care. 37(7): 2034-54. doi:10.2337/dc141140. PMC 5865481. PMID 24935775.

7. National Institute of Diabetes and Digestive and Kidney Diseases. June 2014. Archived from the original on 2 February 2016. Retrieved 10 February 2016.

8. Reddy SC, Kihn YM, Ramil A. Retinopathy in type 2 diabetic patients with microalbuminuria. Nepal J Ophthalmol. 2013 Jan; 5(9): 69-74 
9. Singh DK et al. Mechanisms of disease: the hypoxic tubular hypothesis of diabetic nephropathy. Nat Clin Pract Nephrol 2008; 4: 216-226.

10. Ichinose K, Kawasaki E, Eguchi K. Recent advancement of understanding pathogenesis of type I diabetes and potential relevance to diabetic nephropathy. Am J Nephrol 2007; 27: 554-564.

11. Singh DK, Winocour P, Farrington K. Mechanisms of disease: the hypoxic tubular hypothesis of diabetic nephropathy. Nat Clin Pract Nephrol 2008; 4: 216-226.

12. The Microalbuminuria Collaborative Study Group. Predictors of the development of microalbuminuria in patients with Type I diabetes mellitus: a seven-year prospective study. Diabet Med. 1999 Nov; 16(11): 918-25.

13. Mohan VKA, Nithyanandam S, Jyothi I. Microalbuminuria and low hemoglobin as risk factors for the occurrence and increasing severity of diabetic retinopathy. Indian $\mathbf{J}$ Ophthalmol. 2011 May-Jun; 59(3): 207-210.xer.2000.0882.

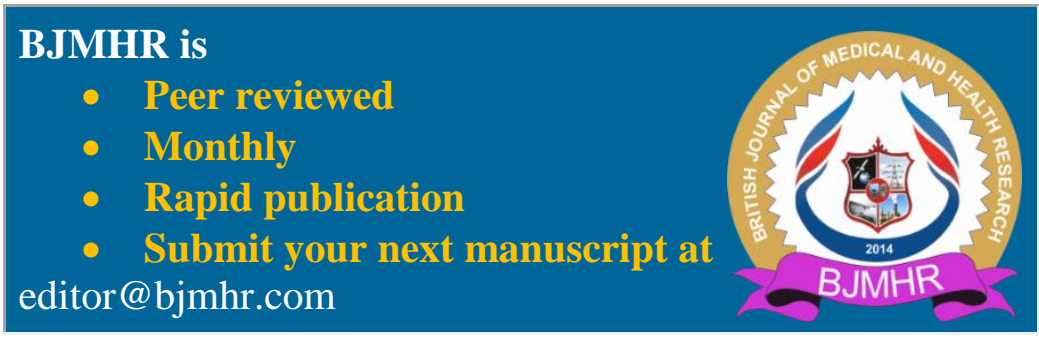

